\title{
Genome-wide Identification of Chile Pepper Pentatricopeptide Repeat Domains Provides Insight into Fertility Restoration
}

\author{
Derek W. Barchenger ${ }^{1}$ and Joseph I. Said ${ }^{2}$ \\ Department of Plant and Environmental Sciences, New Mexico State University, Las Cruces, NM \\ 88003
}

Yang Zhang ${ }^{3}$ and Mingzhou Song
Department of Computer Science, New Mexico State University, Las Cruces, NM 88003

Franchesca A. Ortega

Department of Plant and Environmental Sciences, New Mexico State University, Las Cruces, NM 88003

Yeasong Ha and Byoung-Cheorl Kang

Department of Plant Science, Plant Genomics, and Breeding Institute, and Research Institute for Agriculture and Life Sciences, Seoul National University, Seoul, Republic of Korea

Paul W. Bosland ${ }^{4}$

Department of Plant and Environmental Sciences, New Mexico State University, Las Cruces, NM 88003

\begin{abstract}
ADDITIONAL INDEX wORDs. bioinformatics, chile pepper, cytoplasmic male sterility, hybrid breeding, PPR, restorer of fertility, single nucleotide polymorphism

Abstract. Pentatricopeptide repeat (PPR) proteins constitute one of the largest protein families in plants. They are typically targeted to the mitochondria or chloroplast and bind to one or more organellar transcripts, influencing expression. Genes responsible for inhibiting the mitochondrial genes that cause cytoplasmic male sterility (CMS), restorer-of-fertility $(R f)$ genes, often encode PPRs. Using in silico techniques, 552 PPR domains were identified throughout the chile pepper (Capsicum annuum) genome. The domains were mapped across 12 chromosomes and were found to be largely distally or proximally located. About $28 \%$ of the chile pepper PPR domains identified in this study have high structural similarity to previously reported PPRs in arabidopsis (Arabidopsis thaliana). In addition, 11 candidate $R f$ genes clustered on chromosome 6 , and 1 on chromosome 1 were identified that were characterized in 16 A- (S rfrf), B- (N rfrf), and C-line (N RfRf) backgrounds. These findings support a multigene model for fertility restoration and broaden our understanding of the restoration of fertility. This may be an explanation for the lack of widely applicable molecular markers for this important trait. With this new information, specific $R f$ markers may be developed and will facilitate the implementation of hybrid breeding programs in chile pepper. In addition, this work provides a basis for future research in PPRs, an increasingly important gene family.
\end{abstract}

Chile peppers are native to the arid regions of the Andes Mountains in what is now Peru and Bolivia, and at least 35 wild species have been identified within the genus. As one of the oldest New World crops, chile pepper domestication began $\approx 8000-10,000$ years ago and has resulted in five distinct domesticated species (C. annuum, Capsicum baccatum, Capsicum chinense, Capsicum frutescens, and Capsicum pubescens), with the most widely grown species being $C$. annuum

\footnotetext{
Received for publication 8 Aug. 2018. Accepted for publication 4 Sept. 2018. We thank Sanjeet Kumar and Susan Lin at the World Vegetable Center for providing some of the plant material used for this experiment. We also thank Micheal Young for his technical support.

${ }^{1}$ Current address: The World Vegetable Center, 60 Yi-min Liao Shanhua, Tainan 74151, Taiwan.

${ }^{2}$ Current address: San Jacinto College Central, 8060 Spencer Hwy, Pasadena, TX 77505 .

${ }^{3}$ Current address: Amyris, Inc., 8558 Hollis Street Suite 100, Emeryville, CA 94608.

${ }^{4}$ Corresponding author. E-mail: pbosland@nmsu.edu.
}

(Bosland and Votava, 2012). Chile peppers are cultivated in most parts of the world, particularly in temperate, tropical, and subtropical regions. The fruit of chile peppers are used as a spice and a vegetable, as well as in the extraction industry for food colorants, cosmetics, and pharmaceuticals. Recently, complete chloroplast, mitochondrial, and nuclear genome sequences of chile pepper were made available publicly (Jo et al., 2014; Kim et al., 2014; Park et al., 2016; Qin et al., 2014; Raveendar et al., 2015a, 2015b; Shim et al., 2016; Zeng et al., 2016), enabling genomic exploration to aid in the progress of breeding for important traits.

Because of their degenerate primary sequences, PPR proteins have escaped identification until recently, which has been largely enabled by the availability of complete genomic sequences (Giegé, 2013) and motif scanning algorithms. Characterized by tandem 35 amino acid repeats, PPRs (Small and Peeters, 2000) are ubiquitous among eukaryotes (Giegé, 2013), being one of the largest protein families in land plants with often more than 400 PPR proteins in most species (Barkan 
and Small, 2014). They are RNA-binding proteins encoded in the nucleus and are largely targeted not only to organelles (Giegé, 2013), typically the mitochondria or chloroplasts, but also to nuclear transcripts. Their functions of posttranscriptional processes include RNA editing, splicing, cleavage, and translation (Schmitz-Linneweber and Small, 2008) that have been shown to have major effects on organelle biogenesis and function (Andrés et al., 2007), which in turn have implications for plant development, photosynthesis and respiration, and response to environmental cues (Barkan and Small, 2014). The fundamental physiological functions of organelle genomes have significant directional influence on the evolution of the PPR family; likewise, the expansion of the PPR family has major impacts on the evolution of plant organelle genomes (Barkan and Small, 2014).

The failure to produce functional pollen in the CMS systems is controlled by the plant's mitochondrial genome, and thus CMS is maternally inherited (Ji et al., 2014). Over the past two decades, several types of CMS have been discovered. The two main classes of CMS are sporophytic and gametophytic CMS, in which the sterility of the male gametes is dependent on the genotype of the sporophyte or gametophyte, respectively $(\mathrm{Hu}$ et al., 2014). Chimeric open reading frames (ORF) in the mitochondrial genome generally control CMS and often interfere with electron transport chain genes and, thus, mitochondrial function and pollen development. It has been suggested that the chimeric ORFs result from mitochondrial genome rearrangements (Tuteja et al., 2013). The CMS pathway is one of the more intriguing issues in plants, as only the male gametes are impaired, whereas the female gametes are unaffected $(\mathrm{Hu}$ et al., 2014). It is likely that the male gametes are inhibited because of the high-energy costs associated with pollen production. Many CMS genes have been described in more than 50 species; however, few have been cloned and characterized ( $\mathrm{Hu}$ et al., 2014).

Differing from CMS genes, $R f$ genes are encoded in the nucleus, and act to mask the mitochondrial ORFs that determine CMS, thus restoring fertility (Chase, 2007). The $R f$ genes can function through cleavage or degradation of the CMS-associated mRNA (Wang et al., 2006) and prevent accumulation of the CMS-specific gene product (Bentolila et al., 2002; Kazama et al., 2008). It is proposed that $R f$ genes eliminate the harm caused by CMS products (Cui et al., 1996) and, therefore, natural selection for these genes occurs. Genes that restore fertility are often known to encode PPRs (Chase, 2007; Dahan and Mireau, 2013; Fujii et al., 2011), including the $R f$ gene in petunia [Petunia (Bentolila et al., 2002)]; the $R f o$ (Brown et al., 2003; Deslorie et al., 2003), Rfk 1 (Koizuka et al., 2003), PPR-B (Uyttewaal et al., 2008), RdRf3-4 genes in radish (Raphanus sativus) (Wang et al., 2015); the Rf-1, Rfla (Akagi et al., 2004; Komori et al., 2004; Wang et al., 2006), and Rf1b (Wang et al., 2006) in rice (Oryza sativa); and the $R f 1$ gene in sorghum [Sorghum bicolor (Klein et al., 2005)]. However, other types of $R f$ genes have been cloned; in rice, for example, the $R f 2$ gene encodes a glycine-rich protein and the $R f 17$ gene encodes an unknown protein (Hu et al., 2014), whereas the $R f 2$ in maize (Zea mays) encodes an aldehyde dehydrogenase protein (Cui et al., 1996). For many plant species, CMS/Rf systems are used to produce $\mathrm{F}_{1}$ hybrid seeds, which otherwise involves laborious hand emasculation (Ji et al., 2014). Furthermore, the CMS/Rf system is a model system for the study of nucleocytoplasmic interactions (Budar et al., 2003).
The first reported CMS in chile pepper was by Peterson (1958) in PI 164835 from India. A reliable CMS-associated molecular marker $\left(\mathrm{SCAR}_{130}\right)$ in chile pepper is currently in use (Ji et al., 2014; Jiang, 2015; Yeh et al., 2016). The SCAR 130 is associated with one chimeric ORF (orf507); however, it is likely that other factors, such as orf456 and atp6, are involved in regulation of CMS in chile pepper (Kim and Kim, 2006; Kim et al., 2007). Multiple symptoms have been reported for plant pollen abortion, which is likely due to the presence of multiple CMS-associated ORFs (Fang et al., 2016). Furthermore, CMS in chile pepper is controlled not only by the genotype, but also by external factors, such as temperature (Peterson, 1958; Shifriss and Guri, 1979). Interestingly, the chile pepper $R f$ gene was also identified in an accession derived from PI 164835 (Peterson, 1958). Despite this, the study of CMS and $R f$ interaction in chile pepper is complex and has had inconsistent results (Min et al., 2008). One major issue with the CMS and $R f$ system in Capsicum species is that they seem to be less stable in sweet pepper than in chile pepper (Lin et al., 2015).

Several molecular markers linked to $R f$ in chile pepper have been identified, including OP13 1400 (Zhang et al., 2000), OW18 800 (Lee et al., 2004), OPP13-CAPS (Kim, 2005), AFRF8-CAPS (Kim et al., 2006), PR-CAPS (Lee and Park, 2008), CRF-SCAR (Gulyas et al., 2006), and Co1Mod1 (Jo et al., 2016). Most of the markers linked to $R f$ lack agreement between the phenotype and the marker in diverse populations because of possible $R f$ locus rearrangements (Jiang, 2015; Min et al., 2008), resulting in no broadly applicable markers. Min et al. (2009) reported the markers OPP14 and AFR4 were closely linked to $R f$ in a given population; however, they were unable to accurately detect $R f$ in diverse chile pepper lines. The CRF-SCAR (Gulyas et al., 2006) has been reported to be the most widely applicable indicator of the markers that are available (Jiang, 2015; Jo et al., 2010; Kim et al., 2009; Lin et al., 2015). The CRF-SCAR marker has been used for markerassisted selection to introduce an $R f$ gene into novel germplasm (Lin et al., 2015). More recently, the ColMod1 marker (Jo et al., 2016) has been found to have similar applicability.

Inheritance of restoration-of-fertility in chile peppers has been reported to be controlled by a single gene, one major gene with several minor genes (Peterson, 1958). Several complementary genes (Novak et al., 1971), four quantitative trait loci (Wang et al., 2004), and genes on two different linkage groups (Min et al., 2009) have also been reported to control the phenotype. Furthermore, partial fertility restoration has been reported (Lee, 2001; Lee and Park, 2008) with multiple haplotypes in existence (Min et al., 2008). Liu et al. (2013) found differential expression of several PPR genes between near-isogenic lines for $R f$ and CMS in chile pepper. Although most $R f$ genes have been found to encode PPR proteins, some non-PPR genes have been identified to be closely associated with restoration-of-fertility in chile pepper. For these reasons, it has been proposed that multiple genes or alleles could be involved in restoration-of-fertility of chile pepper.

In arabidopsis, the entire PPR gene family has been identified and expression, localization, and general function studies involving many of the PPR family members have been conducted (Lurin et al., 2004). Conversely in chile pepper, PPR identification has been limited. Jo et al. (2010) used the homologous petunia $R f$ gene (Bentolila et al., 2002) to identify a single PPR [Capsicum annuum pentatricopeptide repeat] 
$(C a P P R 1)]$ gene in chile pepper. Using fine-mapping, Jo et al. (2016) found a candidate $R f$ gene that encodes a PPR protein (CAPPR6). Previous work in other crops has largely focused on identifying a single PPR or a few candidate PPRs.

With the recent release of the chile pepper genome sequences, our objective was to use in silico techniques to provide a comprehensive overview (identification and mapping onto the genome) of the chile pepper PPR domains and to shed light onto the complex genetic mechanisms of restoration-offertility in this increasingly important crop.

\section{Materials and Methods}

The genome sequence of $C$. annuum was obtained from the Chile Pepper Genome Project (Qin et al., 2014). The genome sequence (GCA_000710875.1 v1.0) was then analyzed by MAKER2 (Holt and Yandell, 2011), an annotation and alignment software. The main approach that MAKER2 uses to align known protein sequences to a target genome is to identify exon sequences that can be spliced to match the DNA sequence of a corresponding query protein. Using a spliced-alignment algorithm, MAKER2 aligned the PPR protein queries to the genome and flagged the area as a probable PPR gene. Known PPR proteins from arabidopsis were used to map PPR genes onto the $C$. annuum genome. The entire genome was then data mined manually by observing each probable PPR hit and recording the coordinates of the hit and the fast adaptive shrinkage threshold algorithm (FASTA) sequence. Each putative PPR gene was then stored in FASTA format for further analysis with its coordinates on the genome and chromosome number. Putative PPR genes were then verified using the motif scanner available on the Expert Protein Analysis System (Gasteiger et al., 2003) site that identifies known motifs. Genes that had successive PPR regions were recorded as likely PPR genes and not pseudo PPRs. Each putative PPR that had successive PPR domains was then mapped on its corresponding chromosome, given the base pair coordinates from MAKER2, using BioMercator V3 software (Sosnowski et al., 2012) to create a visual representation of the chromosome and PPR locations. Using a script that we wrote, PPR domain sequences were extracted using the BioStrings package (Pagès et al., 2015) in R [version 3.1.2 (R Core Team, 2017)]. Gene names for each candidate gene were given as " CaPPR" followed by chromosome number and then genes were numbered from the proximal end to the distal end of the chromosome.

For candidate $R f$ gene characterization, 16 accessions with known genotypes including the A-lines ( $\mathrm{S}$ rfrf ) of 'Bukang' and 'Shin Hong'; the B-lines ( $\mathrm{N} r f r f$ ) of 'Bukang', and 'Shin Hong' and 15c1280, and the Zealand).
C-lines (N $R f R f$ ) AVPP9623, AVPP0413, AVPP9905, AVPP0512, AVPP0605, AVPP9807, AVPP0016, AVPP0515, AVPP9904, and AVPP9809; as well as Criollo de Morelos-334 (CM334) (S RfRf) were examined. The cultivars Bukang and Shin Hong are from the Republic of Korea, $15 \mathrm{c} 1280$ is a breeding line from the New Mexico State University chile pepper breeding program, the AVPP C-lines were provided by the World Vegetable Center in Taiwan and are from diverse genetic backgrounds, and CM334 is a landrace from Mexico. Seeds were sown in 96-celled plastic trays (T.O. Plastics, Clearwater, MN). Trays were filled with a commercial peatmossvermiculite soil mixture (RediEarth Plug \& Seedling Mix; Sun Gro Horticulture, Bellevue, WA). Two seeds per cell were sown, and $7 \mathrm{~d}$ after germination, seedlings were thinned to one plant per cell. Trays were placed on propagation pads to maintain the root-zone temperature at $28^{\circ} \mathrm{C}$ and hand-irrigated twice daily. Plants were grown in a climate-controlled greenhouse at the Fabián Garcia Science Center (lat. $32.16^{\circ} \mathrm{N}$, long. $106.46^{\circ} \mathrm{W}$, elevation $1186 \mathrm{~m}$ ) maintained at 28 and $18 \pm 6^{\circ} \mathrm{C}$ day and night temperatures, respectively, with a natural light $12-\mathrm{h}$ photoperiod. Three weeks after sowing, plants were transplanted into 25.4-cm pots filled with a mixture of peatmoss, sand, and native loam soil in a ratio of $1: 1: 1(\mathrm{v}: \mathrm{v})$ and a $18 \mathrm{~N}-2.1 \mathrm{P}-7.6 \mathrm{~K}$ slowrelease fertilizer was applied (Osmocote; Everris International, Geldermalsen, The Netherlands).

DNA was extracted from $\leq 100 \mathrm{mg}$ of young actively growing leaf tissue using the DNeasy Plant mini kit (Qiagen, Hilden, Germany), following the instructions from the manufacturer. Candidate $R f$ domain sequences were obtained using $\mathrm{R}$ and primers were designed in the flanking region (within $100 \mathrm{bp} \mathrm{5}$

Table 1. Flanking region forward and reverse primer pair sequences and annealing temperatures used to amplify Capsicum annuum pentatricopeptide repeat (PPR) domains with similarity to restorerof-fertility genes. All primers were designed using Geneious ${ }^{\circledR}$ (Biomatters, Auckland, New

\begin{tabular}{|c|c|c|}
\hline PPR & Primer sequence $\left(5^{\prime} \rightarrow 3^{\prime}\right)$ & Annealing temp $\left({ }^{\circ} \mathrm{C}\right)$ \\
\hline \multirow{2}{*}{$\overline{C a P P R 1 \_20}$} & CGAGCAAGGAGATTTTCCGTTGCGC & 54 \\
\hline & GTCGCGTATTGTCCCTTTACCGAAT & \\
\hline \multirow[t]{2}{*}{ CaPPR6_35 } & ССТСТTАСТTССТСТССАGTCT & 60 \\
\hline & CTCCATTAACCGGAGCAAGC & \\
\hline \multirow[t]{2}{*}{ CaPPR6_38 } & AGAAGTTGTATGCAAAAATTAGGGC & 57 \\
\hline & ATCAAGTGAAAGAAATATTAACTTC & \\
\hline \multirow[t]{2}{*}{ CaPPR6_39 } & AGTAGCCGAATAAAACAAGAAAGA & 60 \\
\hline & AACTTAGCTGCAGCTATCACCCTTA & \\
\hline \multirow[t]{2}{*}{ CaPPR6_40 } & GTGTTTCCCTGTTCCATTATCCGGA & 54 \\
\hline & GGTAACCATCAATGTTGTGAATGAG & \\
\hline \multirow[t]{2}{*}{ CaPPR6_41 } & CCTACTGTCCAAGCATAAAAAAACC & 61 \\
\hline & GAAGCATCACTCCTCTGATTTCTCT & \\
\hline \multirow[t]{2}{*}{ CaPPR6_42 } & GCAACAAGTTGCTGTTAGCCGGCAT & 60 \\
\hline & CTCGTTCAGAAGGTTGCTAGCAACA & \\
\hline \multirow[t]{2}{*}{ CaPPR6_43 } & AGGGAAAGTCGAAGATGCCGAGGAA & 62 \\
\hline & ATTCCTTATGGGTGCCGTATCTATG & \\
\hline \multirow[t]{2}{*}{ CaPPR6_44 } & GAAGAATTTCTTTAAGTTTGCTACG & 55 \\
\hline & GCAAGATAGTATTGTAGGTAACTGT & \\
\hline \multirow[t]{2}{*}{ CaPPR6_45 } & GGTAAACTCGTCGAAGCTCG & 60 \\
\hline & СCTTCCСТTCGTCTTCCAAA & \\
\hline \multirow[t]{2}{*}{ CaPPR6_46 } & GATGATGACACGTGTCATTTTTGC & 60 \\
\hline & GTATCATGTCAAGGACAGAAGGATTC & \\
\hline \multirow[t]{2}{*}{ CaPPR6_48 } & CGTTCCTAAATAATTGATAGGATTAC & 58 \\
\hline & GAGAGAATGTTTATGAGCCCGACCA & \\
\hline
\end{tabular}

$\mathrm{CaPPR}=$ Capsicum annuum pentatricopeptide repeat. 
upstream and $3^{\prime}$ downstream) of each candidate gene using Geneious ${ }^{\circledR}$ (Biomatters, Auckland, New Zealand) (Table 1), to ensure the entire ORF was sequenced. Oligo DNA primers were ordered from Integrated DNA Technologies (Coralville, IA). Gradient polymerase chain reaction (PCR) was conducted for all primer combinations to optimize the PCRs. The thermocycler reaction involved initial denaturation at $94{ }^{\circ} \mathrm{C}$ for $2 \mathrm{~min}$, followed by 35 cycles of denaturation at $94{ }^{\circ} \mathrm{C}$ for $30 \mathrm{~s}$, annealing for $30 \mathrm{~s}$, and extension at $68^{\circ} \mathrm{C}$ for $1 \mathrm{~min}$, with a final extension at $68{ }^{\circ} \mathrm{C}$ for $5 \mathrm{~min}$. Each PCR contained $\approx 100 \mathrm{ng}$ of DNA, 50\% (v:v) NEBNext ${ }^{\circledR}$ Q5 $^{\circledR}$ Hot Start HiFi PCR master mix (New England BioLabs, Ipswich, MA), $1 \mu \mathrm{M}$ forward primer, $1 \mu \mathrm{M}$ reverse primer, and distilled deionized water $\left(\mathrm{ddH}_{2} \mathrm{O}\right)$ to the final volume. Amplified PCR products were visualized on a $1 \%$ Tris base, boric acid, and ethylenediaminetetraacetic acid agarose gel stained with GelRed ${ }^{\circledR}$ (Biotium, Fremont, CA), and bands were extracted from the gel using the QIAquick gel extraction kit (Qiagen). Gel extracted PCR products were sequenced via the Sanger method by Genewiz (South Plainfield, NJ). Sequences were aligned, polymorphisms were identified, and amino acid sequences were predicted using Geneious ${ }^{\circledR}$. Organelle localization was predicted with the $R f$ candidate genes using several tools, including TargetP (Emanuelsson et al., 2000), scanProsite (de Castro et al., 2006), MultiLoc2 (Blum et al., 2009), SherLoc2 (Briesemeister et al., 2009), and SCLPred (Mooney et al., 2011).

For cytoplasm genotype confirmation, we ran the CMSassociated $\mathrm{SCAR}_{130}$ marker with the DNA from each of the lines used for $R f$ characterization following the methodology reported by Ji et al. (2014). The $R f$-associated CRF marker (Gulyas et al., 2006) and the Co1Mod1 marker (Jo et al., 2016) were run according to the respective methodologies to evaluate for the $R f$ status of each line.

\section{Results}

In the chile pepper genome, 552 PPR domains were identified (Fig. 1; Supplemental Table 1). Chromosome 3 was found to have the most PPR genes at 69, whereas chromosome 10 had the fewest at 25 (Fig. 1; Supplemental Table 1). On most chromosomes, the majority of the PPR genes were found to be proximally or distally clustered with fewer PPRs located in the pericentromeric region (Fig. 1; Supplemental Table 1). Chromosomes 2 and 8 had a large number of PPR genes, 62 and 56, respectively, despite being among the smallest chromosomes in the chile pepper genome, 163.96 and $153.3 \mathrm{Mb}$, respectively (Fig. 1; Supplemental Table 1). The number of PPR genes identified on each chromosome ranged from 28 to 53. The PPR domains within each gene identified here are presented in Supplemental Table 2.

About 28\% of the chile pepper PPR domains identified in this study have high structural similarity to previously reported PPRs (Fig. 2). The proposed gene match, localization, and e-value are listed in Supplemental Table 3. The Arabidopsis Information Resource (Berardini et al., 2015) was used to predict the possible gene function of these PPRs. Most of the PPRs
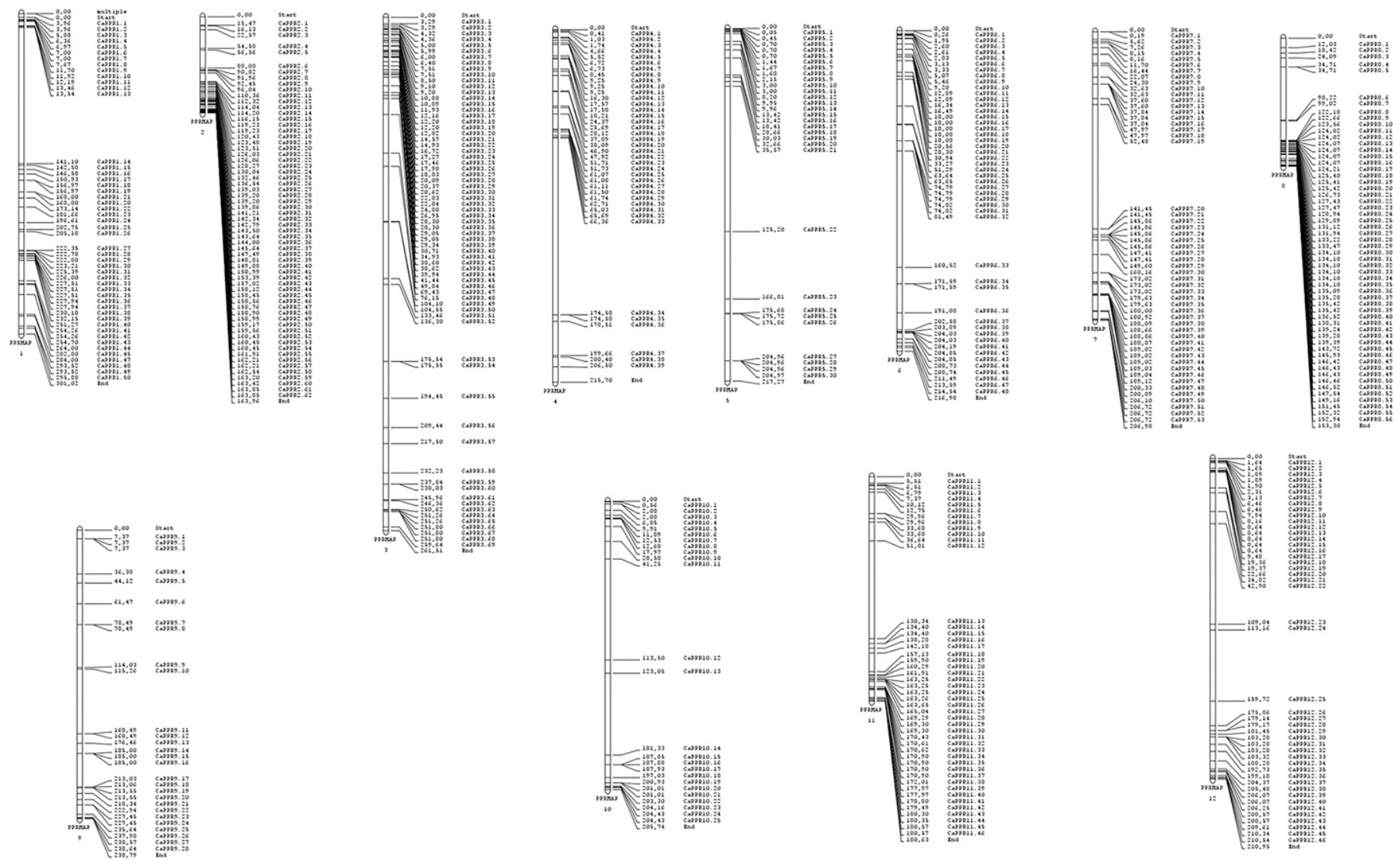

Fig. 1. Chromosome map of the 552 putative Capsicum annuum pentatricopeptide repeat (PPR) domains identified. The PPR domains were identified using the known Arabidopsis thaliana PPRs queried against the chile pepper genome. The number directly to the right of each chromosome is the location of each PPR domain in 10,000 bp. The name given to each PPR domain in this study is to the right of its location. The chromosome number is at the bottom of each map. 


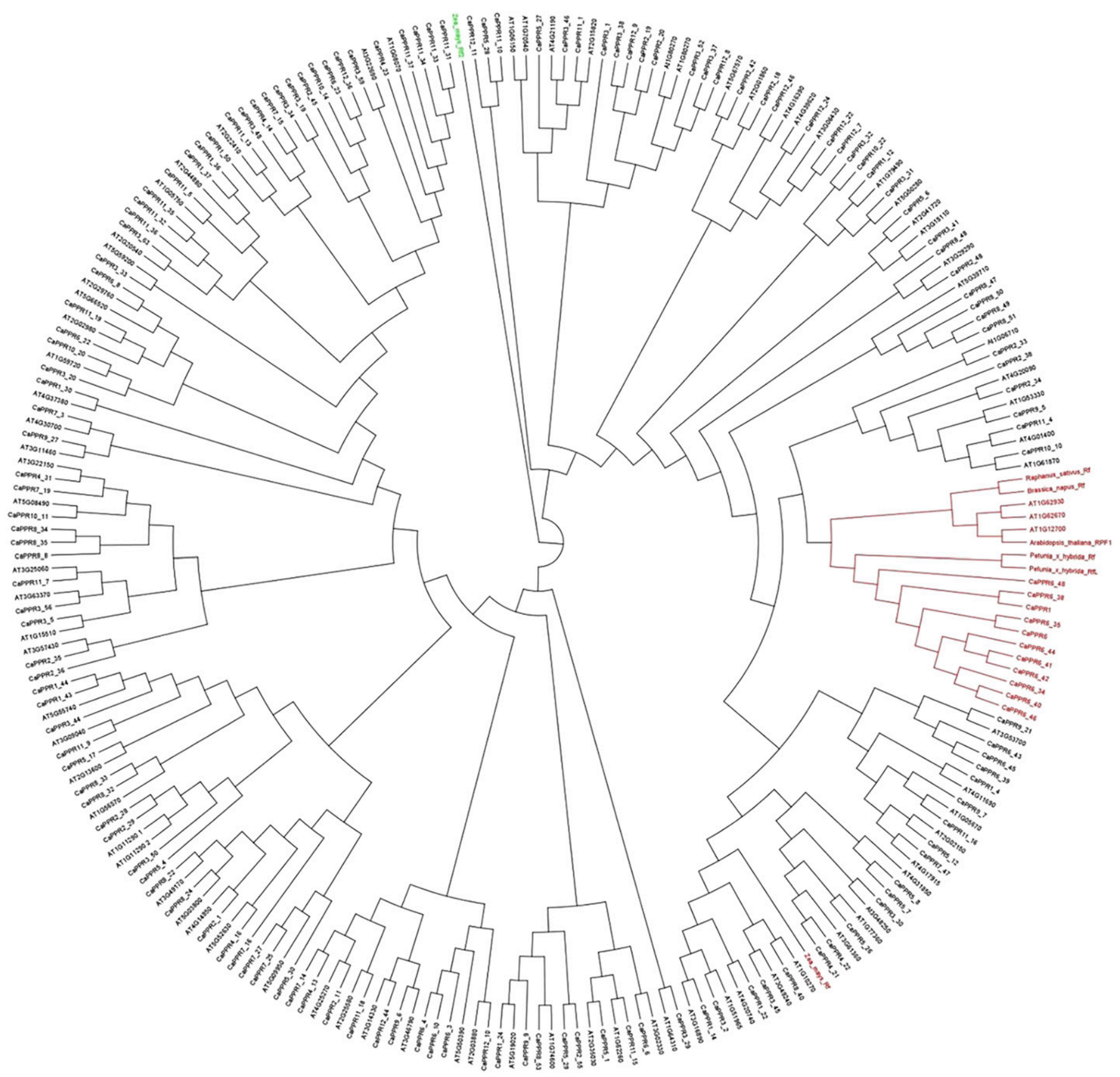

Fig. 2. Phylogenetic tree of the pentatricopeptide repeat protein sequences from the genomes of Capsicum annuum and Arabidopsis thaliana. A maximum likelihood tree was constructed using RAxML (7.2.8) in Geneious ${ }^{\circledR}$ (Biomatters, Auckland, New Zealand) with the GAMMA BLOSUM 62 model with 1000 bootstrap analysis using the multiple sequence alignment of the amino acids created using the Global Geneious Alignment and BLOSUM 62 cost matrix. The candidate restorer-of-fertility $(R f)$ genes are colored red and the root is colored green. $\mathrm{CaPPR}=$ Capsicum annuum pentatricopeptide repeat.

identified were predicted to be localized to the chloroplast or the mitochondria. Chromosome 3 had the largest number (23) of conserved PPR domains. Conserved PPR domains ranged from 5 on chromosome 10 to 18 on chromosome 11 (Supplemental Table 3).

Chile pepper was found to have multiple domains with similarity to previously reported PPRs. One extreme example of this is chromosome 11 that has seven domains that encode proteins with similarity to the PPR protein Organelle Transcript Processing 82 (OTP82). With two target sites in arabidopsis, OTP82 is known to have chloroplast RNA editing capacity
(Hammani et al., 2009). Most importantly, 12 PPR domains that encode proteins with similarity to previously reported $R f$ genes were discovered (Table 2). Domain CaPPR1_20 was located in the pericentromeric region of chromosome 1 . Domains CaPPR6_35, CaPPR6_38 through CaPPR6_46, and CaPPR6_48 were found on the distal end of chromosome 6 (Table 2). The PPR CaPPR6_38 has been previously identified as CaPPR 1 by Jo et al. (2010), based on similarity to the petunia $R f$ gene. These 12 candidate $R f$ genes from chile pepper were more similar to one another than to $R f$ genes of other species, especially when compared with the more divergent monocots 
Table 2. Location and length of Capsicum annuum pentatricopeptide repeat (PPR) domain identified to have similarity to restorer-of-fertility $(R f)$ genes.

\begin{tabular}{lccc}
\hline PPR & Chromosome no. & Domain location (bp) & Domain length (bp) \\
\hline CaPPR1_20 & 1 & $167,995,867$ & 564 \\
CaPPR6_35 & 6 & $174,130,124$ & 213 \\
CaPPR6_38 & 6 & $206,431,066$ & 1,731 \\
CaPPR6_39 & 6 & $206,566,726$ & 1,062 \\
CaPPR6_40 & 6 & $206,567,906$ & 423 \\
CaPPR6_41 & 6 & $206,731,489$ & 468 \\
CaPPR6_42 & 6 & $207,392,625$ & 648 \\
CaPPR6_43 & 6 & $207,393,499$ & 603 \\
CaPPR6_44 & 6 & $211,275,521$ & 537 \\
CaPPR6_45 & 6 & $211,280,934$ & 273 \\
CaPPR6_46 & 6 & $214,033,838$ & 1,752 \\
CaPPR6_48 & 6 & $217,079,895$ & 507 \\
\hline
\end{tabular}

$\mathrm{CaPPR}=$ Capsicum annum pentatricopeptide repeat.

(Table 3). In addition, the $R f$ candidate genes located on chromosome 6 were most similar to each other than to CaPPR1_20, located on chromosome 1 (Table 3; Fig. 3). Despite structural similarity to previously reported $R f$ genes (Table 3), the putative candidate genes CaPPR6_40 and CaPPR6_45 could contain chloroplast target peptide or mitochondrial target peptide, whereas all the other candidate genes are expected to be localized to the mitochondria.

To identify polymorphisms among the candidate PPR genes, they were characterized in 16 A-, B-, and C-lines. Among the 16 lines evaluated and the sequence obtained from the reference genome for CaPPR1_20, 12 single nucleotide polymorphisms (SNPs) were identified, of which three affected the stop codon. Another nine SNPs identified among the A-, B-, and C-lines for CaPPR1_20, which were nonsynonymous mutations, resulted in amino acid substitutions. For CaPPR6_35, six SNPs and one indel were identified across the 16 lines evaluated. Three of the CaPRP6_35 SNPs were nonsynonymous mutations, whereas the insertion resulted in frameshift and polypeptide truncation. CaPPR6_38 had 11 polymorphisms across the $16 \mathrm{~A}-$, B-, and $\mathrm{C}$-lines included in this study. Interestingly, only six of the SNPS resulted in differing amino acids, whereas a microsatellite polymorphism resulted in a lengthening of the polypeptide by a single amino acid. The candidate gene CaPPR6_39 had 10 polymorphisms, but only 5 of these SNPs were nonsynonymous mutations. Because of the high probability that CaPPR6_40 was localized to the chloroplast, it was only characterized in six lines. For CaPPR6_40, three SNPs were found between the accessions evaluated and the extracted genome sequence, an additional two more SNPs were identified between the six A-, B-, and C-lines. Only one SNP was identified for CaPPR6_40 which resulted in an amino acid substitution in the reference genome.

Across the 16 accessions for CaPPR6_41, 10 polymorphisms were found. Of note, there was a T/A SNP in the stop codon that resulted in a longer polypeptide for five of the $\mathrm{C}$ lines and CM334. Of the 10 SNPs identified for CaPPR6_41, eight were nonsynonymous mutations. With CaPPR6_42, 10 SNPs were found across the 16 A-, B-, and C-lines, and 8 SNPs were nonsynonymous. The trinucleotide expansion [AAA (at $572 \mathrm{bp}$ )] resulted in highly variable differences, including an addition of lysine in three lines and a frameshift mutation resulting in a stop codon shift for AVPP9623.

Only two SNPs were found for CaPPR6_43 across the 16 lines evaluated here, and both were nonsynonymous mutations.
For CaPPR6_44, five nonsynonymous mutations were identified across the 16 lines evaluated. With CaPPR6_45 and CaPPR6_46, five of the eight SNPs were nonsynonymous, and 14 of the 17 SNPs identified were nonsynonymous mutations, respectively. One SNP in CaPPR6_46 caused a stop codon in AVPP9905, resulting in a polypeptide 270 amino acids long. CaPPR6_48 had six nonsynonymous mutations, and one was an insertion that resulted in a premature stop codon for AVPP0605. Despite the high diversity in sequences found across these candidate $R f$ genes, no unique polymorphism was identified that could consistently differentiate A- and Clines.

In general, the candidate $R f$ gene polypeptides identified in this study were relatively short. Both CaPPR6_35 and CaPPR6_45 contained two PPR domains and were 71 and 91 amino acids long, respectively. CaPPR6_41 had three PPR domains and was 157 amino acids long, except for those lines with a mutation in the stop codon, which were longer and had an additional PPR domain. CaPPR1_20,CCaPPR6_40, CaPPR6_43, CaPPR6_44, and CaPPR6_48 each contained four PPR domains, and were 177, 140, 201, 179, and 169 amino acids in length, respectively. With the exception of AVPP9623, which has an additional partial PPR domain, CaPPR6_42 had five PPR domains and was 216 amino acids long. CaPPR6_39 was 354 amino acids long and contained 9 PPR domains. CaPPR6_46 had 14 PPR domains and was 583 amino acids long. CaPPR6_38 had 15 PPR domains distributed across its length of 578 amino acids.

To confirm that each accession used to characterize the putative $R f$ genes identified in this study was the correct genotype, we used the publicly available molecular marker SCAR $_{130}$ marker (Ji et al., 2014). As expected, the A-lines and CM334 had sterile cytoplasm and amplicons of $130 \mathrm{bp}$ in length, whereas the C-lines and the NMSU B-line 15c1280 had normal cytoplasm and amplicons of $140 \mathrm{bp}$ in length. In addition, the $R f$-associated CRF (Gulyas et al., 2006) and the Co1Mod1 (Jo et al., 2016) were tested for their efficacy in Cline identification. The CRF marker was found to have $22 \%$ mismatch and the Co1Mod1 marker had 17\% mismatch.

\section{Discussion}

Within land plants, chile pepper has among the most PPR domains at 552 members. The PPR domains of chile peppers were relatively evenly distributed throughout the 3.5-Gbp genome. It might be expected that the larger the genome the more PPR domains a species might have; however, this is not the case. Although having smaller genomes than chile pepper, arabidopsis (135 Mbp) has 450 PPR domains, rice (430 Mbp) has 477 PPR domains, and perennial ryegrass [Lolium perenne (2.7 Gbp)] has 373 PPR domains (Lurin et al., 2004; O'Toole et al., 2008; Sykes et al., 2016). Greater duckweed (Spirodela polyrhiza), a basal monocot native to aquatic environments with a small genome size (158 Mbp), was found to have 556 


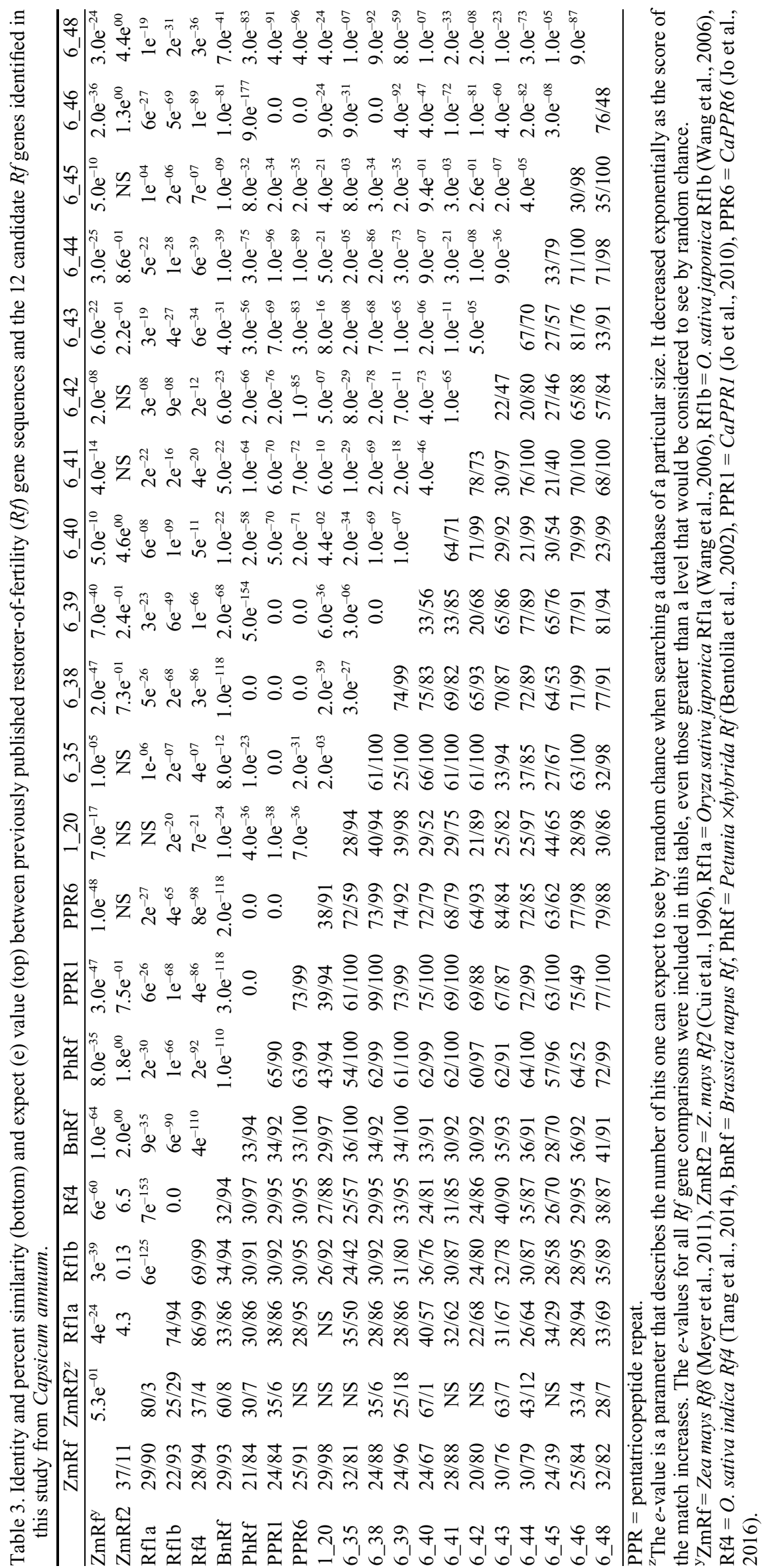



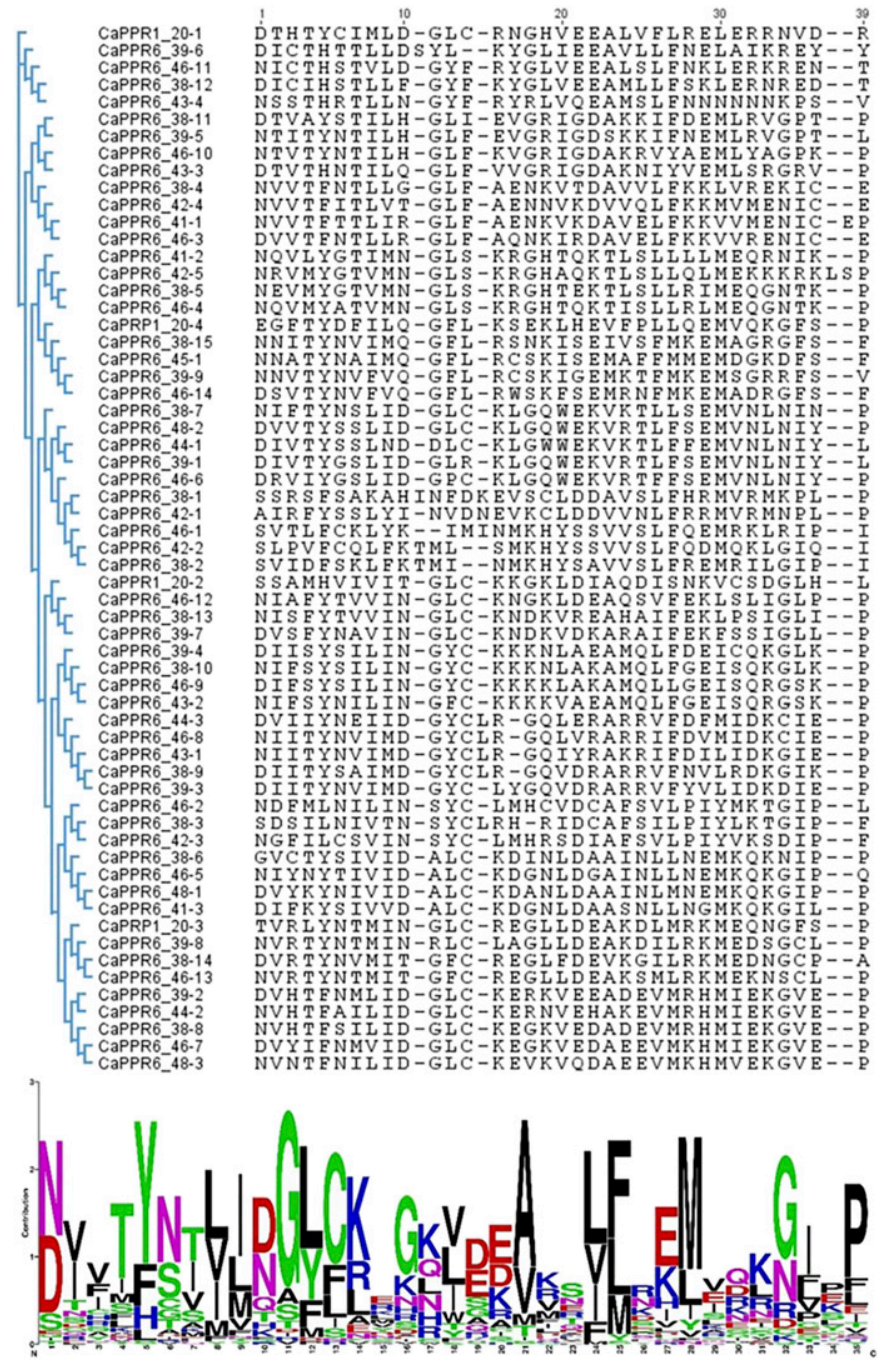

Fig. 3. Phylogenetic tree and logo analysis of the pentatricopeptide repeat domains from the candidate restorer-of-fertility $(R f)$ genes of Capsicum annuиm. Each domain follows the gene name numbered from the first to the last PPR domain within a gene. A maximum likelihood tree was constructed using RAxML (7.2.8) in Geneious ${ }^{\circledR}$ (Biomatters, Auckland, New Zealand) with the GAMMA BLOSUM 62 model with 1000 bootstrap analysis. Logo analysis was conducted using the WebLogo software (Crooks et al., 2004).

PPR domains (Wang et al., 2016). Conversely, green algae [Chlamydomonas reinhardtii $(120 \mathrm{Mbp})$ ] was found to have 154 PPRs (Tourasse et al., 2013). In this study, chromosome size was not necessarily associated with the number of PPR domains. In fact, the smallest chile pepper chromosomes had the most PPR domains. The PPR domain expansion is predicted to have occurred early in the colonization of land plants, as all land plants have many more PPR genes than any algal genome (Barkan and Small, 2014). However, higher order land plants do not necessarily have consistently more or less PPRs than lower order plants. This finding is not entirely surprising because we know that eukaryote genome size does not correlate with organism complexity, as stated in the $C$-value paradox (Eddy, 2012).

It is possible that not every PPR domain in chile pepper was identified in this experiment because of the quality of the reference genome and differences in orthologous genes among species. The driving forces behind the extreme diversity in PPR number are largely unknown (Barkan and Small, 2014).
However, PPR characterization in chile pepper might shed some light on this intriguing problem. Most PPR genes identified here were relatively small, which was expected because of the overall lack of intragenic regions in PPRs (O'Toole et al., 2008; Wang et al., 2016). It has been suggested that the intron-less nature of PPRs could be the result of retrotransposition (Wang et al., 2016). Retrotransposons are sections of the genome that move from place to place by reverse transcription of an RNA transposition intermediate (Finnegan, 2012). Furthermore, retrotransposition would also explain the wide chromosomal distribution across the genome of the PPR gene family. More than $81 \%$ of the chile pepper genome consists of transposons, which is a very high percentage as compared with the closely related tomato [Solanum lycopersicum (50\%)] and potato [Solanum tuberosum (47\%)] (Qin et al., 2014). Therefore, the diversity observed in PPR domain number might be associated with transposons and not necessarily genome size or organism complexity.

The PPR gene content is similar across angiosperms (Barkan and Small, 2014), with $>80 \%$ of arabidopsis and rice PPR proteins forming orthologous pairs in phylogenetic trees (O'Toole et al., 2008). It is likely that high conservation of both protein activity and target sequences in the organellular genome exists across species (Barkan and Small, 2014). For example, the MPPR6 protein in maize is directly involved in the $5^{\prime}$ maturation and translation initiation of rps 3 mRNA in the mitochondria, which can complement the loss-of-function mutant in arabidopsis that lacks the orthologous protein (Manavski et al., 2012).

One intriguing group of highly conserved PPR genes is the P-class of $R f$-like $(R F L)$ genes (Fujii et al., 2011). The $R F L$ genes form a separate clade from other PPR genes across diverse plant species, implying that they originated from the same ancestral gene that existed before the speciation of land plants (Fujii et al., 2011). This monophyletic origin has also been hypothesized to have occurred before monocot/dicot division (Gaborieau et al., 2016). This could also help explain the existence of a single $R f$ candidate gene (CaPPRI_20) located in the pericentromeric region of chromosome 1, which may be a more ancestral gene as compared with the other $R f$ genes. Plant species have around 10-30 RLFs within their genomes (Andrés et al., 2007; Fujii et al., 2011). Similar to the 12 identified in chile pepper, Fujii et al. (2011) identified 33 $R F L$ from A. lyrata, 26 from arabidopsis, 9 from purple false brome (Brachypodium distachyon), 41 from soybean (Glycine max), 13 from common yellow monkeyflower (Mimulus guttatus), 13 from japonica rice (O. sativa ssp. japonica), 14 from rice, 20 from black cottonwood (Populus trichocarpa), 21 from sorghum, 10 from grape (Vitis vinifera), and 5 from maize. It is also possible that individual $R F L s$, beyond the 12 identified in chile pepper, could have been overlooked because of incomplete genome assemblies that are publically available.

$R F L s$ appear to be under different selection pressures when compared with the rest of the PPR gene family. The RFL genes have higher rates of nonsynonymous to synonymous substitutions, as compared with other PPR genes (Fujii et al., 2011), and the chile pepper $R f$ candidate genes also had high sequence similarity, often in the range of $70 \%$ to $80 \%$ (Table 3 ).

In this study, the $R f$ candidate genes characterized were largely located at the distal end of chromosome 6, supporting previous reports (Jo et al., 2010, 2016; Wang et al., 2004). It has been found that cloned PPR-type $R f$ and $R F L$ genes typically 
form a cluster with closely located PPR genes, whereas other PPR genes are dispersed throughout the genome (Lurin et al., 2004; Wang et al., 2006), and these clustered PPRs share high sequence similarity (Jo et al., 2016). This is all evidence, in conjunction with gene duplication, that the generation of new $R F L$ genes and subsequent loss of nonfunctional RFLs is relatively rapid, and keeps pace with the generation of novel CMS sources (Sykes et al., 2016). It is known that the source of novel CMS mechanisms within the mitochondrial genome has high rates of recombination (Kubo et al., 2011; Sloan et al., 2012). Therefore, RFLs likely serve as a pool from which new $R f$ genes can emerge (Gaborieau et al., 2016).

The likelihood of PPR encoding $R f$ genes occurring in the regions of active $R F L$ generation is a function of the time required for fertility restoration to become fixed within a population as well as the rate that $R F L$ genes are shuffled throughout the genome (Sykes et al., 2016). It has been suggested that if the rate of fixation is faster than the rate of shuffling, $R f$ genes will always be found within these $R F L$ clusters (Sykes et al., 2016). It appears that RFLs are shuffled around the genome at a rate faster than that of speciation and are being rapidly lost when nonfunctional (Dahan and Mireau, 2013).

Pentatricopeptide repeats function through attachment to target mRNA, preventing or interfering with translation. This attachment occurs at the fourth and 34th amino acids within each of the PPR domains (Manna, 2015). These attachment points are important for function, e.g., a single nonsynonymous mutation at the fourth amino acid in one PPR domain completely inhibited function of Proton Gradient Regulation 3 (Fujii et al., 2013). In addition, it has been shown that the rate of diversifying selection is the highest on the first, third, and sixth amino acids of the PPR motif, which may be involved with RNA ligand interaction. Each 35-amino acid array of a PPR protein determines the specificity of the protein to one nucleotide of target mRNA. Furthermore, a combination of the first and sixth amino acids in the motif is crucial for determining specificity, implying that these amino acids likely interact directly with the target mRNA (Barkan and Small, 2014; Barkan et al., 2012). Several of the $R f$ candidate genes had nonsynonymous mutations at these key amino acid locations (Table 4). Each of these polymorphisms could influence target specificity as well as mRNA attachment, and therefore, play

Table 4. Pentatricopeptide repeat (PPR) domains of Capsicum annuum restorer-of-fertility $(R f)$ candidate genes with polymorphisms at key amino acids associated with PPR attachment, specificity, and diversifying selection.

\begin{tabular}{lcccccr}
\hline & \multicolumn{5}{c}{ Amino acid location } \\
\cline { 2 - 6 } PPR gene & First & Third & Fourth & Fifth & Sixth & 34th \\
\hline CaPPR1_20 & \multirow{2}{*}{ z } & & $6,11,12$ & & & 3 \\
CaPPR6_38 & $6^{\mathrm{z}}$ & & 8 & & \\
CaPPR6_39 & & 2 & & 4 & \\
CaPPR6_41 & & & & & 5 \\
CaPPR6_42 & & & 5,12 & 5 & 6 \\
CaPPR6_44 & \multirow{2}{*}{ CaPPR6_46 } & 11 & 4 & 3 & & \\
CaPPR6_48 & & & & & \\
\hline
\end{tabular}

$\mathrm{CaPPR}=$ Capsicum annuum pentatricopeptide repeat.

${ }^{\mathrm{z}}$ Pentatricopeptide repeat domain designation within the $R f$ candidate genes with polymorphisms at key amino acid locations. a role in their function. Therefore, it is possible that multiple genes can play a role in restoring fertility in chile pepper.

The lack of a widely applicable marker associated with $R f$ in chile pepper can be explained by the varying levels in phenotype and marker agreement identified in this study. However, recently developed markers are becoming more widely applicable. It is possible that for some chile pepper accessions, one major $R f$ gene is required to confer a fertile phenotype, whereas for other accessions multiple small effect genes might be required for fertility restoration. Igarashi et al. (2016) found that multiple $R f$ genes may be required to restore fertility in rice. It is possible that the single $R f C a P P R 6 \_38$ plays a major role in restoration of fertility for the cultivar Bukang, whereas multiple small effects genes could be required to restore fertility in 'Shin Hong'. This is because there were no SNPs between the A- and B-lines of 'Shin Hong' or the C-lines for CaPPR6_38, previously identified as CaPPR1 by Jo et al. (2010); however, there was a microsatellite polymorphism between the A-line of 'Bukang' and C-lines. Conversely, it was relatively rare that polymorphisms occurred between the A-line of 'Bukang' and C-lines in the other 11 candidate genes, whereas polymorphisms between the A-line of 'Shin Hong' and the $\mathrm{C}$-lines were common. It was possible to differentiate the Aand C-lines of 'Shin Hong' with two SNPs in CaPPR1_20, three SNPs in CaPP6_35, seven SNPs in CaPPR6_39, two SNPs in CaPPR6_41, and five SNPs in CaPPR6_46 (previously identified as CaPPR6) (Jo et al., 2016). This is further evidence that different $R f$ genes could function in different Aand C-lines. In other crops, multiple $R f$ genes have been identified to be functional. Two $R f$ genes have been identified in rice (Hu et al., 2012; Luo et al., 2013; Wang et al., 2006). Furthermore, multiple haplotypes have been identified for an allele of an $R f$ gene in sugar beet [Beta vulgaris (Ohgami et al., 2016)]. Multiple haplotypes could exist for the $R f$ candidate genes identified here. This inference is supported by a lack of a consistent polymorphism associated with a particular phenotype. In addition to the 12 candidate genes identified, $R f$ genes that do not encode for PPRs could also play a role in restoring fertility in chile pepper. This phenomenon has been observed in maize (Cui et al., 1996).

Gene expression studies using microarrays and reverse transcription polymerase chain reaction amplification have shown that only $\approx 45 \%$ of PPR gene expression is detectable in plants (Lurin et al., 2004; Wang et al., 2016). Therefore, it is difficult to determine which of the candidate $R f$ genes identified in this study are actually functional. Furthermore, because of the lack of a consistent polymorphism associated with a particular phenotype, it is challenging to develop a more widely applicable molecular marker to evaluate in a segregating population. In addition, PPRs also have multiple functions, and therefore, expression studies are not accurate. For example, PPR96 was found to be involved in plant responses to salinity, abscisic acid, and oxidative stress in arabidopsis (Liu et al., 2016). Several studies found that PPR genes are subject to regulatory control by siRNA, miRNA, and tasiRNA (Allen et al., 2004; Chen et al., 2007; Howell et al., 2007; Park et al., 2014; Rhoades et al., 2002; Sunkar and Zhu, 2004). Indels in the untranslated regions of PPRs have been found to play a role in their functionality. Therefore, untranslated areas upstream of the PPR genes and other regulatory elements could play a role in $R f$ gene function in chile pepper, which has been observed in radish (Wang et al., 2017). Nevertheless, sequence differences 
within the $R f$ genes play a role in loss of function. In radish, a 26-bp deletion within the $R s R f 3$ gene in addition to two point mutations resulted in loss of function of the gene (Wang et al., 2015).

\section{Conclusions}

In this study, the PPR domains of chile pepper were identified and mapped. In addition, the $R f$ candidate genes of chile pepper in 16 accessions were characterized, providing insights into the lack of widely applicable molecular markers for the $R f$ gene, and possible causes of the instability of the $\mathrm{CMS} / R f$ system in chile pepper. This work provides plant breeders with possible targets for program-specific $R f$ marker development and will facilitate the more rapid implementation of hybrid breeding schemes in chile pepper. In addition, the PPR domains identified in this study also provide a basis for work in other important areas, including transcript regulation, seedling lethality, and hormone sensitivity. The predominance of transposons in the chile pepper genome might be associated with PPR expansion and the findings presented here could be used to better understand the evolutionary forces driving the high number of PPR domains in land plants.

\section{Literature Cited}

Akagi, H., A. Nakamura, Y. Yokozeki-Misono, A. Inagaki, H. Takahashi, K. Mori, and T. Fujimura. 2004. Positional cloning of the rice $r f-1$ gene, a restorer of bt-type cytoplasmic male sterility that encodes a mitochondria-targeted PPR protein. Theor. Appl. Genet. 108:1449-1457.

Allen, E., Z. Xie, A.M. Gustafson, G.H. Sung, J.W. Spatafora, and J.C. Carrington. 2004. Evolution of microRNA genes by inverted duplication of target gene sequences in Arabidopsis thaliana. Nat. Genet. 36:1282-1290.

Andrés, C., C. Lurin, and I.D. Small. 2007. The multifarious roles of PPR proteins in plant mitochondrial gene expression. Physiol. Plant. 129:14-22.

Barkan, A., M. Rojas, S. Fujii, A. Yap, Y.S. Chong, C.S. Bond, and I. Small. 2012. A combinatorial amino acid code for RNA recognition by pentatricopeptide repeat proteins. PLoS Genet. 8(8):e1002910.

Barkan, A. and I. Small. 2014. Pentatricopeptide repeat proteins in plants. Annu. Rev. Plant Biol. 65:415-442.

Bentolila, S., A.A. Alfonso, and M.R. Hanson. 2002. A pentatricopeptide repeat-containing gene restores fertility to cytoplasmic malesterile plants. Proc. Natl. Acad. Sci. USA 99:10887-10892.

Berardini, T.Z., L. Resier, D. Li, Y. Mezheritsky, R. Muller, E. Strait, and E. Huala. 2015. The arabidopsis information resource: Making and mining the "Gold Standard" annotated reference plant genome. Genesis 53:474-485.

Blum, T., S. Briesemeister, and O. Kohlbacher. 2009. MultiLoc: Integrating phylogeny and gene ontology terms improves subcellular protein localization prediction. BMC Bioinformatics 10:274.

Bosland, P.W. and E.J. Votava. 2012. Peppers: Vegetable and spice capsicums. 2nd ed. CAB International, Wallingford, UK.

Briesemeister, S., T. Blum, S. Brady, Y. Lam, O. Kohlbacher, and H. Shatkay. 2009. SherLoc2: A high-accuracy hybrid method for predicting subcellular localization of proteins. J. Proteome Res. 8:5363-5366.

Brown, G.G., N. Formanova, H. Jin, R. Wargachuk, C. Dendy, P. Patil, M. Laforest, J. Zhang, W.Y. Cheung, and B.S. Landry. 2003. The radish $R f o$ restorer gene of Ogura cytoplasmic male sterility encodes a protein with multiple pentatricopeptide repeats. Plant J. 35:262-272. Budar, F., P. Touzet, and R. de Paepe. 2003. The nucleo-mitochondrial conflict in cytoplasmic male sterilities revisited. Genetica 117:3.
Chase, C.D. 2007. Cytoplasmic male sterility: A window to the world of plant mitochondrial-nuclear interactions. Trends Genet. 23:81-90.

Chen, H.M., Y.H. Li, and S.H. Wu. 2007. Bioinformatic prediction and experimental validation of microRNA-directed tandem trans-acting siRNA cascade in Arabidopsis. Proc. Natl. Acad. Sci. USA 104:3318-3323.

Crooks, G.E., G. Hon, J.M. Chandonia, and D.W. Brenner. 2004. WebLogo: A sequence logo generator. Genome Res. 14:1188-1190.

Cui, X., R.P. Wise, and P.S. Schnable. 1996. The $r f 2$ nuclear restorer gene of male-sterile T-cytoplasm maize. Science 272:1334-1336.

Dahan, J. and H. Mireau. 2013. The $R f$ and $R f$-like PPR in higher plants, a fast evolving subclass of PPR genes. RNA Biol. 10:12861293.

de Castro, E., C.J.A. Sigrist, A. Gattiker, V. Bulliard, P.S. LangendijkGenevaux, E. Gasteiger, A. Bairoch, and N. Hulo. 2006. ScanProsite: Detection of PROSITE signature matches and ProRul-associated functional and structural residues in proteins. Nucl. Acids Res. 34: W362-W365.

Deslorie, S., H. Gherbi, W. Laloui, S. Maradour, V. Clouet, L. Cattolico, C. Falentin, S. Giancola, M. Renard, F. Budar, I.D. Small, M. Caboche, R. Delourme, and A. Bendahmane. 2003. Identification of the fertility restoration locus, $R f o$, in radish, as a member of the pentatricopeptide-repeat protein family. EMBO Rpt. 4:588-594.

Eddy, S.R. 2012. The C-value paradox, junk DNA and ENCODE. Curr. Biol. 22:898-899.

Emanuelsson, O., H. Neilsen, S. Brunak, and G. von Heijne. 2000. Predicting subcellular localization of proteins based on their Nterminal amino acid sequence. J. Mol. Biol. 300:1005-1016.

Fang, X., H.F. Fu, Z.H. Gong, and W.G. Chai. 2016. Involvement of a universal amino acid synthesis impediment in cytoplasmic male sterility in pepper. Sci. Rpt. 6:23357.

Finnegan, D.J. 2012. Retrotransposons. Curr. Biol. 11:R432-R437.

Fujii, S., C.S. Bond, and I.D. Small. 2011. Selection patterns on restorer-like genes reveal a conflict between nuclear and mitochondrial genomes throughout angiosperm evolution. Proc. Natl. Acad. Sci. USA 108:1723-1728.

Fujii, S., N. Sato, and T. Shikanai. 2013. Mutagenesis of individual pentatricopeptide repeat motifs affects RNA binding activity and reveals functional partitioning of Arabidopsis PROTON GRADIENT REGULATION3. Plant Cell 25:3079-3088.

Gaborieau, L., G.G. Brown, and H. Mireau. 2016. The propensity of pentatricopeptide repeat genes to evolve into restorers of cytoplasmic male sterility. Front. Plant Sci. 7:1816.

Gasteiger, E., A. Gattiker, C. Googland, I. Ivanyi, R.D. Appel, and A. Bairoch. 2003. ExPASy: The proteomics server for in-depth protein knowledge and analysis. Nucl. Acids Res. 31:3784-3788.

Giegé, P. 2013. Pentatricopeptide repeat proteins: A set of modular RNA-specific binders massively used for organelle gene expression. RNA Biol. 10:1417-1418.

Gulyas, G., K. Pakozdi, J.S. Lee, and Y. Hirata. 2006. Analysis of fertility restoration by using cytoplasmic male-sterile red pepper (Capsicum annuum L.) lines. Breeding Sci. 56:331-334.

Hammani, K., K. Okunda, S.K. Tanz, A.L. Chateigner-Boutin, T. Shikanai, and I. Small. 2009. A study of new Arabidopsis chloroplast RNA editing mutants reveals general features of editing factors and their target sites. Plant Cell 21:3685-3699.

Holt, C. and M. Yandell. 2011. MAKER2: An annotation pipeline and genome-database management tool for second-generation genome projects. BMC Bioinformatics 12:491.

Howell, M.D., N. Fahlgren, E.J. Chapman, J.S. Cumbie, C.M. Sullivan, S. A. Givan, K.D. Kasschau, and J.C. Carrington. 2007. Genome-wide analysis of the RNA-DEPENDENT RNA POLYMERASE6/DISERLIKE4 pathway in Arabidopsis reveals dependency on miRNA- and tasiRNA-directed targeting. Plant Cell 19:926-942.

Hu, J., W. Huang, Q. Huang, X. Qin, C. Yu, L. Wang, S. Li, R. Zhu, and Y. Zhu. 2014. Mitochondria and cytoplasmic male sterility in plants. Mitochondrion 19:282-288. 
Hu, J., K. Wang, W. Huang, G. Lio, Y. Gao, J. Wang, Q. Huang, Y. Ji, X. Qin, L. Wan, R. Zhu, S. Li, D. Yang, and Y. Zhu. 2012. The rice pentatricopeptide repeat protein $R f 5$ restores fertility in Hong-Lian cytoplasmic male sterile lines via a complex with the glycine rich protein GRP162. Plant Cell 24:109-122.

Igarashi, K., T. Kazama, and K. Toriyama. 2016. A gene encoding pentatricopeptide repeat protein partially restores fertility in RT98type cytoplasmic male-sterile race. Plant Cell Physiol. 57:2187-2193. Ji, J.J., W. Huang, Y.X. Yin, Z. Li, and Z.H. Gong. 2014. Development of a SCAR marker for early identification of S-cytoplasm based on mitochondrial SRAP analysis in pepper (Capsicum annuum L.). Mol. Breeding 33:679-690.

Jiang, L. 2015. Utilizing classical and molecular approached to breeding for disease resistant hybrid chile peppers (Capsicum). New Mexico State Univ., Las Cruces, PhD Diss.

Jo, Y.D., Y. Choi, D.H. Kim, B.D. Kim, and B.C. Kang. 2014. Extensive structural variation between mitochondrial genomes of CMS and normal peppers (Capsicum annuum L.) revealed by complete nucleotide sequencing. BMC Genomics 15:561.

Jo, Y.D., Y. Ha, J.H. Lee, M. Park, A.C. Bergsma, H.I. Choi, S. Gortischnig, B. Kloosterman, P.J. van Dijk, D. Choi, and B.C. Kang. 2016. Fine mapping of Restorer-of-fertility in pepper (Capsicum annuum L.) identified a candidate gene encoding a pentatricopeptide repeat (PPR)-containing protein. Theor. Appl. Genet. 129:20032017.

Jo, Y.D., Y.M. Kim, M.N. Park, J.H. Yoo, M. Park, B.D. Kim, and B.C. Kang. 2010. Development and evaluation of broadly applicable markers for Restorer-of-fertility in pepper. Mol. Breeding 25:187201.

Kazama, T., T. Nakamura, M. Watanbe, M. Sugita, and K. Toriyama. 2008. Suppression mechanism of mitochondrial ORF79 accumulation by $R f 1$ protein in BT-type cytoplasmic male sterile rice. Plant J. 55:619-628.

Kim, D.S. 2005. Development of RAPD and AFLP markers linked to fertility restorer $(R f)$ gene in chili pepper (Capsicum annuum L.). Seoul Natl. Univ., Seoul, Korea, MS Thesis.

Kim, Y.M., Y.D. Jo, and B.C. Kang. 2009. Haplotype analysis of CMS-associated DNA markers in sweet peppers. J. Crop Sci. Biotechnol. 12:129-134.

Kim, D.H., J.G. Kang, and B.D. Kim. 2007. Isolation and characterization of cytoplasmic male sterility-associated orf456 gene of chili pepper (Capsicum annuum L.). Plant Mol. Biol. 63:519-532.

Kim, D.S. and B.D. Kim. 2006. The organization of mitochondrial atp6 gene region in male fertile and CMS lines of pepper (Capsicum annuum L.). Curr. Genet. 49:59-67.

Kim, D.S., D.H. Kim, J.H. Yoo, and B.D. Kim. 2006. Cleaved amplified polymorphic sequence and amplified fragment length polymorphism markers linked to the fertility restorer gene in chili pepper (Capsicum annuum L.). Mol. Cells 21:135-140.

Kim, S., M. Park, S.I. Yeom, Y.M. Kim, J.M. Lee, H.A. Lee, E. Seo, J. Choi, K. Cheong, K.T. Kim, K. Jung, G.W. Lee, S.K. Oh, C. Bae, S.B. Kim, H.Y. Lee, S.Y. Kim, M.S. Kim, B.C. Kang, Y.D. Jo, H.B. Yang, H.J. Jeong, W.H. Kang, J.K. Kwon, C. Shin, J.Y. Lim, J.H. Park, J.H. Huh, J.S. Kim, B.D. Kim, O. Cohen, I. Paran, M.C. Suh, S.B. Lee, Y.K. Kim, Y. Shin, S.J. Noh, J. Park, Y.S. Seo, S.Y. Kwon, H.A. Kim, J.M. Park, H.J. Kim, S.B. Choi, P.W. Bosland, G.R. Reeves, S.H. Jo, B.W. Lee, H.T. Cho, H.S. Choi, M.S. Lee, Y. Yu, Y. Do Choi, B.S. Park, A. van Deynze, H. Ashrafi, T. Hill, W.T. Kim, H.S. Pai, H.K. Ahn, I. Yeam, J.J. Giovannoni, J.K.C. Rose, I. Sorensen, S.J. Lee, R.W. Kim, I.Y. Choi, B.S. Choi, J.S. Lim, Y.H. Lee, and D. Choi. 2014. Genome sequence of the hot pepper provides insights into the evolution of pungency in Capsicum species. Nat. Genet. 46:470-478.

Klein, R.R., P.E. Klein, J.E. Mullet, P. Minx, W.L. Rooney, and K.F. Schertz. 2005. Fertility restorer locus RfI of sorghum (Sorghum bicolor $\mathrm{L}$.) encodes a pentatricopeptide repeat protein not present in the collinear region of rice chromosome 12. Theor. Appl. Genet. 111:994-1012.
Koizuka, N., R. Imai, H. Fujimoto, T. Hayakawa, Y. Kimura, J. Kohno-Murase, T. Sakai, S. Kawasaki, and J. Imamura. 2003. Genetic characterization of a pentatricopeptide repeat protein gene, orf687, that restores fertility in the cytoplasmic male-sterile Kosena radish. Plant J. 34:407-415.

Komori, T., S. Ohta, N. Murai, Y. Takakura, Y. Kuraya, S. Suzuki, Y. Hiei, H. Imaseki, and N. Nitta. 2004. Map-based cloning of a fertility restorer gene, $R f-1$, in rice (Oryza sativa L.). Plant J. 37:315-325.

Kubo, T., K. Kitazaki, M. Matsunaga, H. Kagami, and T. Mikami. 2011. Male sterility-inducing mitochondrial genomes: How do they differ? Crit. Rev. Plant Sci. 30:378-400.

Lee, D.H. 2001. Studies on unstable fertility of CGMS (cytoplasmicgenic male sterility) in Capsicum annuum L. Seoul Natl. Univ., Seoul, Korea, PhD Diss.

Lee, J.M., S.H. Nahm, Y.M. Kim, and B.D. Kim. 2004. Characterization and molecular genetic mapping of microsatellite loci in pepper. Theor. Appl. Genet. 108:619-627.

Lee, J.J.B.Y. and H.G. Park. 2008. Linkage analysis between the partial restoration $(\mathrm{pr})$ and the restorer-of-fertility $(R f)$ loci in pepper cytoplasmic male sterility. Theor. Appl. Genet. 117:383-389.

Liu, C., N. Ma, P.Y. Wang, N. Fu, and H.L. Shen. 2013. Transcriptome sequencing and de novo analysis of cytoplasmic male sterile lines and its near-isogenic restorer line in chili pepper (Capsicum annuum L.). PLoS One 8(6):e65209.

Lin, S.W., H.C. Shieh, Y.W. Wang, C.W. Tan, R. Schafleitner, W.J. Yang, and S. Kumar. 2015. Restorer breeding in sweet pepper: Introgressing $R f$ allele from hot pepper through marker-assisted backcrossing. Scientia Hort. 197:170-175.

Liu, J.M., J.Y. Zhao, P.P. Lu, M. Chen, C.H. Guo, Z.S. Xu, and Y.Z. Ma. 2016. The E-subgroup pentatricopeptide repeat protein family in Arabidopsis thaliana and confirmation of the responsiveness PPR96 to abiotic stress. Front. Plant Sci. 7:1825.

Luo, D., H. Xu, Z. Liu, J. Guo, H. Li, L. Chen, C. Fang, Q. Zhang, M. Bai, N. Yao, H. Wu, C. Ji, H. Zhang, Y. Chen, S. Ye, X. Li, X. Zhao, R. Li, and Y.G. Liu. 2013. A detrimental mitochondrial-nuclear interaction causes cytoplasmic male sterility in rice. Nat. Genet. 45:573-577.

Lurin, C., C. Andrés, S. Aubourg, M. Bellaoui, F. Bitton, C. Bruyère, M. Caboche, C. Debast, J. Gualberto, B. Hoffmann, A. Lechamy, M. Le Ret, M.L. Martin-Magniette, H. Mireau, N. Peeters, J.P. Renou, B. Szurek, L. Taconnat, and I. Small. 2004. Genome-wide analysis of Arabidopsis pentatricopeptide repeat proteins reveals their essential role in organelle biogenesis. Plant Cell 16:2089-2103.

Manavski, N., V. Guyon, J. Meurer, U. Wienand, and R. Brettschneider. 2012. An essential pentatricopeptide repeat protein facilitates $5^{\prime}$ maturation and translation of rps 3 mRNA in maize mitochondria. Plant Cell 24:3087-3105.

Manna, S. 2015. An overview of pentatricopeptide repeat proteins and their applications. Biochimie 113:93-99.

Meyer, J., D. Pei, and R.P. Wise. 2011. Rf8-mediated T-transcript accumulation coincides with a pentatricopeptide repeat cluster on maize chromosome 2L. Plant Genome 4:283-299.

Min, W.K., S. Kim, S.L. Sung, B.D. Kim, and S. Lee. 2009. Allelic discrimination of the Restorer-of-fertility gene and its inheritance in peppers (Capsicum annuum L.). Theor. Appl. Genet. 119:1289-1299. Min, W.K., H. Lim, Y.P. Lee, S.K. Sung, B.D. Kim, and S. Kim. 2008. Identification of a third haplotype of the sequence linked to the restorer-of-fertility $(R f)$ gene and its implications for malesterility phenotypes in peppers (Capsicum annuum L.). Mol. Cells 25:20-29.

Mooney, C., Y.H. Wang, and G. Pollastri. 2011. SCLpred: Protein sublocalization prediction by $\mathrm{N}-1$ neutral networks. Bioinformatics 27:2812-2819.

Novak, F., J. Betlach, and J. Dubovsky. 1971. Cytoplasmic male sterility in sweet pepper (Capsicum annuum L.) I. Phenotype and inheritance of male sterile character. Zeitschrift fur Pflanzenzüchtung 65:129-140.

Ohgami, T., D. Uchiyama, S. Ue, R. Yui-Kurino, Y. Yoshisa, Y. Kamei, Y. Kuroda, K. Taguchi, and T. Kubo. 2016. Identification of 
molecular variants of the nonrestoring restorer-of-fertility 1 allele in sugar beet (Beta vulgaris L.). Theor. Appl. Genet. 129:675-688.

O'Toole, N., M. Hattori, C. Andres, K. Iida, C. Lurin, C. SchmitzLinneweber, M. Sugita, and I. Small. 2008. On the expansion of the pentatricopeptide repeat gene family in plants. Mol. Biol. Evol. 25:1120-1128.

Pagès, H., P. Aboyoun, R. Gentleman, and S. DeRoy. 2015. Biostrings: Strings objects representing biological sequences, and matching algorithms R Package V 2.42.1.

Park, Y.J., H.J. Lee, K.J. Kwak, K. Lee, S.W. Hong, and H. Kang. 2014. MicroRNA400-guided cleavage of pentatricopeptide repeat protein mRNAs renders Arabidopsis thaliana more susceptible to pathogenic bacteria and fungi. Plant Cell Physiol. 55:1660-1668.

Park, H.S., J. Lee, S.C. Lee, T.J. Yang, and J.B. Yoon. 2016. The complete chloroplast genome sequence of Capsicum chinense Jacq. (Solanaceae). Mitochondrial DNA B Resources 1:164-165.

Peterson, P.A. 1958. Cytoplasmically inherited male sterility in Capsicum. Amer. Natl. 92:111-119.

Qin, C., C. Yub, Y. Shena, X. Fang, L. Chen, J. Mind, J. Cheng, S. Zhao, M. Xu, Y. Luo, Y. Yang, Z. Wu, L. Mao, H. Wu, C. Ling-Hu, H. Zhou, H. Lin, S. Gonzailez-Morales, D.L. Trejo-Saavedra, H. Tian, X. Tang, M. Zhao, Z. Huang, A. Zhou, X. Yao, J. Cui, W. Li, Z. Chen, Y. Feng, Y. Niu, S. Bi, X. Yang, W. Li, H. Cai, X. Lu, S. Montes-Hernaìndez, M.A. Leyva-Gonzailez, Z. Xiong, X. He, L. Bai, S. Tan, X. Tang, D. Liu, J. Liu, S. Zhang, M. Chen, L. Zhang, L. Zhang, Y. Zhang, W. Liao, Y. Zhang, M. Wang, X. Lv, B. Wen, H. Liu, H. Luan, Y. Zhang, S. Yang, X. Wang, J. Xu, X. Li, S. Li, J. Wang, A. Palloix, P.W. Bosland, Y. Li, A. Krogh, R.F. RiveraBustamante, L. Herrera-Estrella, Y. Yin, J. Yu, K. Hu, and Z. Zhang. 2014. Whole-genome sequencing of cultivated and wild peppers provides insights into Capsicum domestication and specialization. Proc. Natl. Acad. Sci. USA 111:5135-5140.

Raveendar, S., Y.A. Jeon, J.R. Lee, G.A. Lee, K.J. Lee, G.T. Cho, K.H. Ma, S.Y. Lee, and J.W. Chung. 2015a. The complete chloroplast genome sequence of Korean landrace "Subicho" pepper (Capsicum annuum var. annuum). Plant Breeding Biotechnol. 3:88-94.

Raveendar, S., Y.W. Na, J.R. Lee, D. Shim, K.H. Ma, S.Y. Lee, and J. W. Chung. 2015b. The complete chloroplast genome of Capsicum annuum var. glabriusculum using Illumina sequencing. Molecules 20:13080-13088.

R Core Team. 2017. R: A language and environment for statistical computing. R Foundation Stat. Computing, Vienna, Austria.

Rhoades, M.W., B.J. Reinhart, L.P. Lim, C.B. Burge, B. Bartel, and D.P. Bartel. 2002. Prediction of plant microRNA targets. Cell 110:513-520. Schmitz-Linneweber, C. and I. Small. 2008. Pentatricopeptide repeat proteins: A socket set for organelle gene expression. Trends Plant Sci. 13:663-670.

Shifriss, C. and A. Guri. 1979. Variation in stability of cytoplasmic male sterility in C. annuum. J. Amer. Soc. Hort. Sci. 104:94-96.

Shim, D., S. Raveendar, J.R. Lee, G.A. Lee, N.Y. Ro, Y.A. Jeon, G.T. Cho, H.S. Lee, K.H. Ma, and J.W. Chung. 2016. The complete chloroplast genome of Capsicum frutescens (Solanaceae). Appl. Plant Sci. 4:1600002.

Sloan, D.B., A.J. Alverson, J.P. Chuckalovak, M. Wu, D.E. McCauley, J.D. Palmer, and D.R. Taylor. 2012. Rapid evolution of enormous, multichromosomal genomes in flowering plant mitochondria with exceptionally high mutation rates. PLoS Biol. 10:e1001241.
Small, I. and N. Peeters. 2000. The PPR motif-a TPR related motif prevalent in plant organellar proteins. Trends Biochem. Sci. 25:45-47. Sosnowski, O., A. Charcosset, and J. Joets. 2012. BioMercator V3. Bioinformatics 28:2082-2083.

Sunkar, R. and J.K. Zhu. 2004. Novel and stress-regulated microRNAs and other small RNA from Arabidopsis. Plant Cell 16:20012019.

Sykes, T., S. Yates, I. Nagy, T. Asp, I. Small, and B. Studer. 2016. In silico identification of candidate genes for fertility restoration in cytoplasmic male sterile perennial ryegrass (Lolium perenne L.). Genome Biol. Evol. 9:351-362.

Tang, H., D. Luo, D. Zhou, Q. Zhang, D. Tian, Z. Zhang, L. Chen, and Y.G. Liu. 2014. The rice restorer $R f 4$ for wild-abortive cytoplasmic male sterility encodes a mitochondrial-localized PPR protein that functions in reduction of WA352 transcripts. Mol. Plant 7:14791500 .

Tourasse, N.J., Y. Choquet, and O. Vallon. 2013. PPR proteins of green algae. RNA Biol. 10:1526-1532.

Tuteja, R., R.K. Saxena, J. Davila, T. Shah, W. Chen, Y.I. Xiao, G. Fan, K.B. Saxena, A.J. Alverson, C. Spillane, C. Town, and R.K. Varshney. 2013. Cytoplasmic male sterility-associated chimeric open reading frames identified by mitochondrial genome sequencing of four cajanus genotypes. DNA Res. 20:485-495.

Uyttewaal, M., N. Amal, M. Quadrado, A. Martin-Canadell, N. Vrielynck, S. Hiard, H. Gherbi, A. Bendahmane, F. Budar, and H. Mireau. 2008. Characterization of Raphanus sativus pentatricopeptide repeat proteins encoded by a fertility restorer locus for Ogura cytoplasmic male sterility. Plant Cell 20:3331-3345.

Wang, Z.W., C.D. Wang, Q.Z. Cai, S.W. Mei, L. Gau, Y. Zhou, and T. Wang. 2017. Identification of promoter exchange at a male fertility restorer locus for cytoplasmic male sterility in radish (Raphanus sativus L.). Mol. Breeding 37:82.

Wang, Z.W., C.D. Wang, S.Y. Mei, L. Gao, Y. Zhou, and T. Wang. 2015. An insertion-deletion at a pentatricopeptide repeat locus linked to fertility transition to cytoplasmic male sterility in radish (Raphanus sativus L.). Mol. Breeding 25:1-5.

Wang, W., Y. Wu, and J. Massing. 2016. Genome-wide analysis of pentatricopeptide-repeat proteins of an aquatic plant. Planta 244:893-899.

Wang, L.H., B.X. Zhang, V. Lefebvre, S.W. Huang, A.M. Daubeze, and A. Palloix. 2004. QTL analysis of fertility restoration in cytoplasmic male sterile pepper. Theor. Appl. Genet. 109:1058-1063.

Wang, Z., Y. Zou, X. Li, Q. Zhang, L. Chen, H. Wu, D. Su, Y. Chen, J. Guo, D. Luo, Y. Long, Y. Zhong, and Y. Liu. 2006. Cytoplasmic male sterility of rice with boro II cytoplasm is caused by a cytotoxic peptide and is restored by two related PPR motif genes via distinct modes of mRNA silencing. Plant Cell 18:676-687.

Yeh, T., S. Lin, H. Shieh, Y. Teoh, and S. Kumar. 2016. Markers for cytoplasmic male sterility (CMS) traits in chili peppers (Capsicum annuum L.). I: Multiplex PCR and validation. Soc. Adv. Breeding Res. Asia Oceania J. Breeding Genet. 48:465-473.

Zeng, F.C., C.W. Gao, and L.Z. Gao. 2016. The complete chloroplast genome sequence of American bird pepper (Capsicum annuum var. glabriusculum). Mitochondrial DNA 27:724-726.

Zhang, B.X., S. Huang, G.W. Yang, and J.Z. Guo. 2000. Two RAPD markers links to a major fertility restorer gene in pepper. Euphytica 113:155-161. 